\title{
CASE REPORT \\ Safety and efficacy of a new device for inducing ejaculation in men with spinal cord injuries
}

\author{
SM Castle, LC Jenkins, E Ibrahim, TC Aballa, CM Lynne and NL Brackett
}

Study design: Prospective case series.

Objectives: Male infertility is a common sequela of spinal cord injury (SCI). Fatherhood is a goal in this group of young patients; however, most are anejaculatory. Penile vibratory stimulation is recommended as the first line of treatment for this condition. Our study evaluated the safety and efficacy of a new device designed to induce ejaculation in these patients.

Setting: The Miami Project to Cure Paralysis, Miami, FL, USA.

Methods: The Viberect-X3 (Reflexonic, Frederick, MD, USA) was applied to 30 consecutive anejaculatory men with SCI whose level of injury was T10 and rostral.

Results: The ejaculatory success was $77 \%$ (23/30). No adverse events occurred, and there were no malfunctions of the device. Conclusion: In this first report on the efficacy of the Viberect-X3 for treatment of anejaculation in men with $\mathrm{SCl}$, we conclude that the device is safe and effective for inducing ejaculation in men with $\mathrm{SCl}$. Recommendation of the Viberect-X3 versus other devices intended for this purpose should not be made until randomized controlled trials are performed.

Spinal Cord (2014) 52, S27-S29; doi:10.1038/sc.2014.110

\section{INTRODUCTION}

Every year, there are $\sim 12000$ new cases of spinal cord injury (SCI) in the United States, ${ }^{1}$ and thousands more worldwide. Most spinal cord injuries occur in young males. ${ }^{1}$ Following SCI, the majority of men become anejaculatory and require medical assistance to procure sperm. $^{2}$ Only $10 \%$ of men with SCI can ejaculate via masturbation. ${ }^{3}$

Owing to its safety, cost and reliability, penile vibratory stimulation (PVS) is recommended as the first line of therapy for anejaculation in men with SCI. ${ }^{3}$ PVS typically is performed by applying a single vibrator to the dorsum or frenulum of the glans penis. During any PVS procedure, care must be taken to manage adverse symptoms such as autonomic dysreflexia and penile skin edema/abrasion., ${ }^{4,5}$ Historically, a wide variety of ejaculation success rates (19-96\%) have been reported from PVS of men with SCI, with the highest success rates achieved by devices capable of delivering amplitudes $\geqslant 2.5 \mathrm{~mm}$ and $100 \mathrm{~Hz}$, applied to men whose level of injury was T10 and rostral. ${ }^{3,6,7}$

Failures (22\%) may be salvaged by 'sandwiching' the penis between two vibrators; ${ }^{8}$ however, this maneuver can be cumbersome to perform. A new vibrator has been developed to achieve, in a single device, simultaneous stimulation of the dorsum and frenulum of the penis (Viberect-X3, Reflexonic, Frederick, MD, USA; Figure 1). To date, there are no reports on the efficacy of this device for inducing ejaculation in men with SCI. The purpose of our study was to evaluate the ejaculatory success rate and safety of the Viberect-X3 in anejaculatory patients with SCI.

\section{MATERIALS AND METHODS}

The study was approved by our Institutional Review Board. Subjects were men with SCI enrolled in the Male Fertility Research Program of the Miami Project to Cure Paralysis. All signed informed consent documents. We prospectively studied 30 consecutive SCI subjects who were unable to ejaculate by sexual intercourse or masturbation. Ejaculatory response to PVS relies on an intact spinal reflex $\operatorname{arc}^{3}{ }^{3}$ therefore, subjects with injuries caudal to T10 were excluded from the study. All patients received one trial of PVS with Viberect-X3. All patients were familiar with PVS and had been administered one or more previous trials with an alternate device. The present study was not designed to compare the success rates of various PVS devices, but simply to assess the ejaculation success rate with Viberect-X3.

Prior to PVS, subjects whose level of injury was T6 or rostral were administered $10-40 \mathrm{mg}$ nifedipine sublingually to manage autonomic dysreflexia. Viberect-X3 was administered at the non-adjustable manufacturer settings of $4 \mathrm{~mm}$ amplitude and $70-100 \mathrm{~Hz}$. Based on our previous studies, PVS was performed in $2-5$ min intervals, interspersed by $1-2$ min rest periods, for up to three intervals of stimulation, or until ejaculation occurred. ${ }^{3}$ Blood pressure was recorded at $1 \mathrm{~min}$ intervals throughout the procedure. Each patient was monitored for adverse symptoms, including penile bleeding or edema. The vibrator pads were thoroughly cleansed with $70 \%$ alcohol between each patient use.

\section{RESULTS}

Details of patient information are listed in Table 1. The result of the PVS procedures was that 23 of the 30 patients $(76.7 \%)$ ejaculated. No adverse symptoms were noted. All patients tolerated the procedure well. The Viberect-X3 device did not malfunction during any of the stimulations. 


\section{DISCUSSION}

PVS is thought to cause ejaculation via stimulation of the dorsal penile nerve. ${ }^{9}$ In order to achieve ejaculation, the penile vibrator must

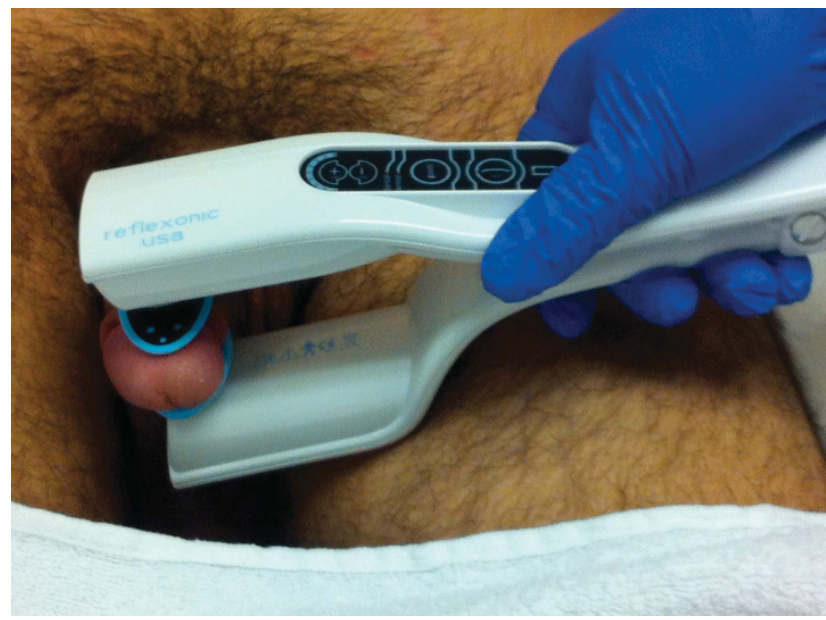

Figure 1 Viberect-X3 (Reflexonic, Frederick, MD, USA) is a new device for inducing ejaculation in men with spinal cord injury. The device can stimulate, simultaneously, the dorsum and frenulum of the glans penis, via two vibrating surfaces, as seen here. appropriately stimulate this nerve. Earlier reports showed lowamplitude vibrators to be inferior to high-amplitude vibrators for inducing ejaculation in men with SCI. ${ }^{10}$ Viberect-X3 deploys high-amplitude $(4 \mathrm{~mm})$ vibration via two sites in a single device. Viberect-X3 represents a new option for these patients. The success rate obtained in our study (76.7\%) was slightly lower than previously published PVS success rates. ${ }^{3}$ This new penile vibrator appears to be safe and reliable in our cohort. For practitioners who have administered PVS with other devices, the learning curve is quite short, that is, one to two trials should be sufficient to successfully administer Viberect-X3. Prior to the patient self-administering this device at home, an experienced practitioner should supervise the patient's ability to safely and effectively administer the Viberect-X3.

Previous research has described maneuvers to salvage patients who fail to ejaculate with the administration of one single-headed vibrator. Such maneuvers include sandwiching the penis between two single-headed vibrators, administration of abdominal electrical stimulation in conjunction with PVS and administration of medications such as midodrine (for a review, see Brackett et al. ${ }^{3}$ ). The current study did not assess the ability of Viberect-X3 to salvage failures to a single-headed vibrator.

In this first report on the efficacy of Viberect-X3 for treatment of anejaculation in men with SCI, we conclude that the device is safe and effective for inducing ejaculation in men with SCI at or rostral to T10.

\section{Table 1 Patient demographics and ejaculation trial outcomes}

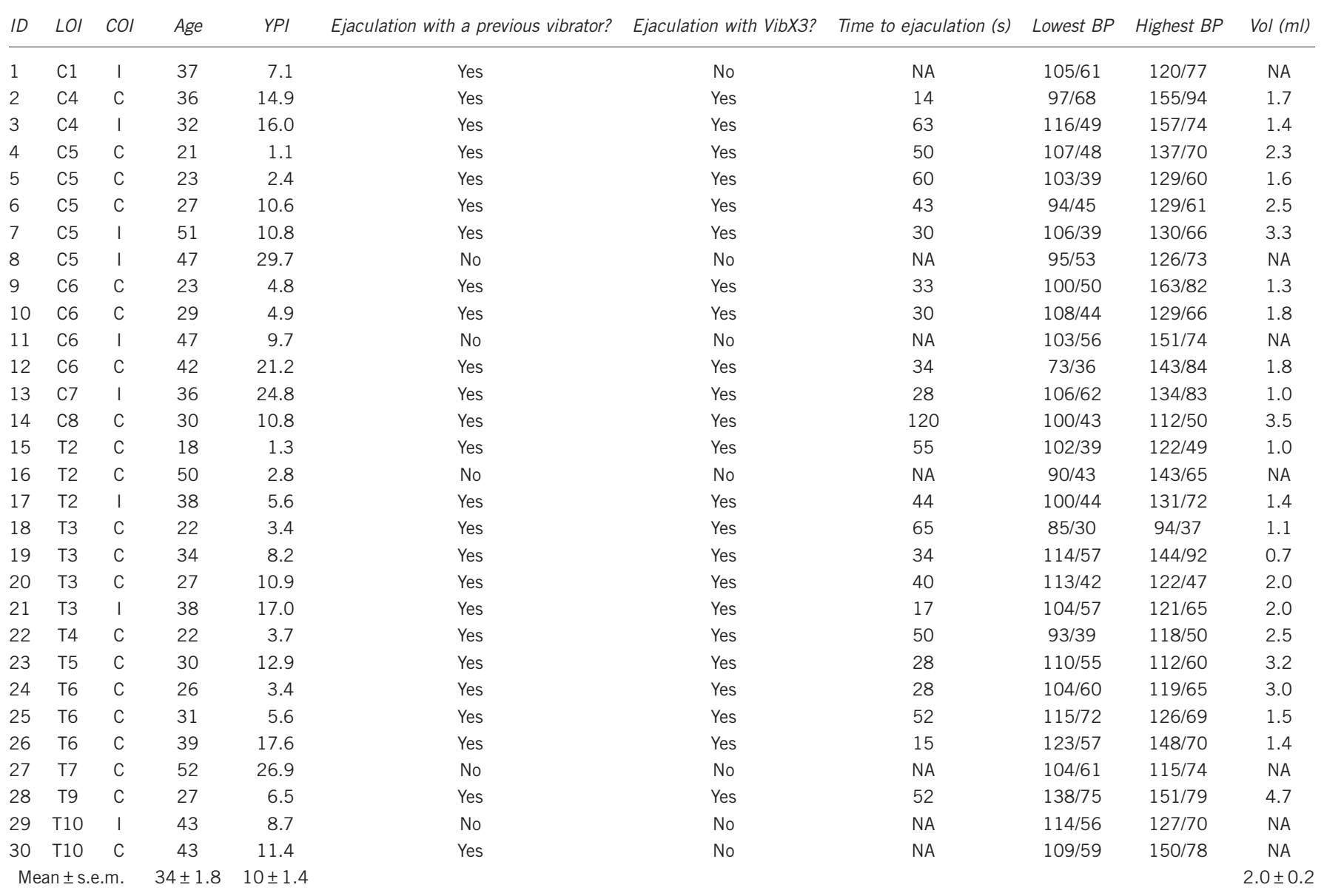

Abbreviations: BP, blood pressure; C\#, cervical; C, complete; COI, completeness of injury; Ejac with Prev Vib?, Did the patient ejaculate when administered a previous PVS trial with an alternate device (not the Viberect-X3)?; Ejac with VibX3?, Did the patient ejaculate with the Viberect-X3?; I, incomplete; ID, subject ID; LOI, level of injury; NA, not applicable; T, thoracic; Time to Ejac, How many seconds it took for the patient to ejaculate with Viberect-X3; Vol, Antegrade semen volume in milliliters; YPI, years post injury. 
Recommendation of Viberect-X3 versus other devices intended for this purpose should not be made until randomized controlled trials are performed.

\section{DATA ARCHIVING}

There were no data to deposit.

\section{CONFLICT OF INTEREST}

The authors declare no conflict of interest.

1 National SCl Statistical Center. Spinal Cord Injury-Facts and Figures at a Glance, 2013, available from https://www.nscisc.uab.edu/PublicDocuments/fact_figures_docs/ Facts\%202013.pdf.

2 Brown DJ, Hill ST, Baker HW. Male fertility and sexual function after spinal cord injury. Prog Brain Res 2006; 152: 427-439.

3 Brackett NL, Lynne CM, Ibrahim E, OhI DA, Sonksen J. Treatment of infertility in men with spinal cord injury. Nat Rev Urol 2010; 7: 162-172.

4 Elliott S, Krassioukov A. Malignant autonomic dysreflexia in spinal cord injured men. Spinal Cord 2006; 44: 386-392.

5 Brackett NL, Lynne CM, Sonksen J, OhI D. Penile vibratory stimulation. In: Goldstein M and Schlegel PN (ed) Surgical and Medical Management of Male Infertility, 1st edn. Cambridge University Press: New York, 2013, pp 119-129.
6 Sonksen J, OhI DA. Penile vibratory stimulation and electroejaculation in the treatment of ejaculatory dysfunction. Int J Androl 2002; 25: 324-332.

7 Sonksen J, Biering-Sorensen F, Kristensen JK. Ejaculation induced by penile vibratory stimulation in men with spinal cord injuries. The importance of the vibratory amplitude. Paraplegia 1994; 32: 651-660.

8 Brackett NL, Kafetsoulis A, Ibrahim E, Aballa TC, Lynne CM. Application of 2 vibrators salvages ejaculatory failures to 1 vibrator during penile vibratory stimulation in men with spinal cord injuries. J Urol 2007; 177: 660-663.

9 Wieder J, Brackett N, Lynne C, Green J, Aballa T. Anesthetic block of the dorsal penile nerve inhibits vibratory-induced ejaculation in men with spinal cord injuries. Urology 2000; 55: 915-917.

10 Brackett NL, Ferrell SM, Aballa TC, Amador MJ, Padron OF, Sonksen J et al. An analysis of 653 trials of penile vibratory stimulation in men with spinal cord injury. J Urol 1998; 159: 1931-1934.

\section{(c) (i)}

This work is licensed under a Creative Commons Attribution 3.0 Unported License. The images or other third party material in this article are included in the article's Creative Commons license, unless indicated otherwise in the credit line; if the material is not included under the Creative Commons license, users will need to obtain permission from the license holder to reproduce the material. To view a copy of this license, visit http:// creativecommons.org/licenses/by/3.0/ 